\title{
The temporal course of extra-experimental interference from verbal habits
}

\author{
DONALD E. PRYOR ${ }^{1}$ AND KENNETH A. BLICK ${ }^{2}$
} RANDOLPH-MACON COLLEGE

\begin{abstract}
After training with a paired-associate learning task, retention was assessed by the verbal stimulation technique after 2 min and $48 \mathrm{~h}$. A significant loss in retention from 2 min to $48 \mathrm{~h}$ was accompanied by a corresponding increase in extraexperimental sources of interference. Proactive interference due to pre-experimental verbal habits was found to increase as the retention interval increased.
\end{abstract}

Underwood \& Postman (1960) have suggested that extra-experimental sources account for a considerable amount of verbal forgetting. Extra-experimental sources refer to an individual's language habits which exist previous to the experimental situation and which may interfere with the recall of new verbal material learned in the laboratory.

The separate experiments of Coleman (1963) and Spence (1963) with association hierarchies in which they found evidence of pre-existing associations causing interference in novel learning situations have given additional meaning to the work done by Bilodeau, Fox, \& Blick (1963), who shifted the emphasis in verbal memory from frequency of usage to cultural norm associative probabilities. Bilodeau et al (1963) have shown that the cultural norms of Russell \& Jenkins (1954) have considerable power in accounting for what other Ss will say in a recall context.

Russell \& Jenkins (1954) published norms for words given in discrete free-association to the $100 \mathrm{Kent}-$ Rosanoff stimulus words. Each stimulus word evoked a number of response words which were arranged in a hierarchical order of frequency. Bilodeau et al (1963) examined the norms of Russell-Jenkins and calculated the associative probabilities for $R_{1}$, the most frequent response, $R_{2}$, the second most frequent, and $R_{3-n}$, all remaining words. In addition, they were able to delineate three categories of stimulus words which they subsequently found useful in predicting correct and incorrect recall.

The present experiment was designed to show that pre-experimental language habits will interfere with what is recalled as a direct function of time, and furthermore, to pinpoint which verbal habits cause the most interference. It was predicted that correct responses would decrease over time, and that simultaneously, the probability of extra-experimental sources ( $R_{1} s$ and $\left.R_{3-n} s\right)$ would increase.

Method

Fifty-four freshmen at Randolph-Macon College were unsystematically divided into two groups of 27 . One group was tested for recall 2 min after training, and the other group was tested for recall $48 \mathrm{~h}$ after training.

The basic apparatus consisted of six pages in booklet form suitable for training and testing large groups. The six sheets were arranged in the following sequence, opaque cover page, page of directions, training page, middle opaque page, vowel cancellation page, and recall page.

All Ss received 10 pairs of words on the training page. Each pair consisted of a stimulus word and a response word which had a cultural probability of being associated with the stimulus word of .01 , according to the Russell-Jenkins norms. Three of the 10 pairs of stimulus and response words are presented in Table 1 under the heading, S-R pairs used in experiment. Note also that the primary or most frequently occurring response word $\left(\mathbf{R}_{1}\right)$, and the secondary response word $\left(R_{2}\right)$, are presented along with their respective associative probabilities. A final category of response words from the Kent-Rosanoff Hierarchy refers to the probability of occurrence of all response words from $R_{3}$ to $\mathbf{R}_{\mathbf{n}}$. During training, for example, the Ss learned to associate "eat" to "table," an association which had an initial S-R cultural probability of .01. However, during recall the $S$ might well respond with "chair" or "food" or some other response that can be found in the normative data.

A total of $20 \mathrm{sec}$ was allowed for training in each group, with the instructions on the training page reading: "Study the pairs shown below. Do not turn the page until you are told to do so." After training, the 2-min group was given $60 \mathrm{sec}$ to close their booklets and to change seats and an additional $60 \mathrm{sec}$ to cancel vowels, thus totaling $2 \mathrm{~min}$ between training and recall. The $48-\mathrm{h}$ group turned in their booklets after training, and $48 \mathrm{~h}$ later they returned and were immediately given $60 \mathrm{sec}$ to cancel vowels. Following vowel cancelation, both groups were instructed to turn to the recall page and proceed according to the following directions: "A while ago you studied several pairs of words. Beside the appropriate stimulus words write in as many of the

Table 1. Russell-Jenkins Associative Probabilities for Three of the Ten Selected Pairs and for the Extra-Experimental Sources of Interference.

\begin{tabular}{|c|c|c|c|c|c|c|c|}
\hline \multicolumn{3}{|c|}{$\begin{array}{c}\text { S-R Pairs } \\
\text { Used in Experiment }\end{array}$} & \multicolumn{5}{|c|}{$\begin{array}{c}\text { Extra-Experimental } \\
\text { Sources of Interference }\end{array}$} \\
\hline Stimulus & Response & S-R Prob. & $\mathrm{R}_{1}$ & $\mathrm{p}\left(\mathrm{R}_{1}\right)$ & $\mathbf{R}_{2}$ & $p\left(R_{2}\right)$ & $p\left(R_{3-n}\right)$ \\
\hline Table & Eat & .01 & Chair & .84 & Food & .04 & .11 \\
\hline Blossom & Pink & .01 & Flower & .67 & Apple & .08 & .24 \\
\hline Light & Window & .01 & Dark & .65 & Lamp & .08 & .26 \\
\hline
\end{tabular}


Table 2. Obtained Response Probabilities for the Ten Stimulus Words Classified by Retention Interval and Source of Recall.

\begin{tabular}{lcccccc} 
Retention & Correct & \multicolumn{5}{c}{ Extra-Experimental Sources } \\
\cline { 3 - 7 } Interval & Response & $\mathrm{R}_{1}$ & $\mathrm{R}_{2}$ & $\mathrm{R}_{3-\mathrm{n}}$ & Extraneous & Blank \\
\hline $2 \mathrm{~min}$ & .64 & .21 & .01 & .10 & .04 & .00 \\
$48 \mathrm{~h}$ & .31 & .43 & .02 & .18 & .05 & .01 \\
\hline Free-Assoc. & .01 & .72 & .05 & .22 & - & - \\
\hline
\end{tabular}

response words as you can remember. If you cannot remember, write in the first, word that the stimulus word makes you think of. You must fill in every line. Do not look back to the previous page."

Results

All responses given during the recall session are accounted for in Table 2 where the rows display the effect of the two retention periods, 2 min and $48 \mathrm{~h}$. The associative probabilities for the 10 stimulus words were obtained under the discrete free-association procedure and are presented in the last row of the table in order to provide a meaningful control comparison. The columns indicate the probability of responses attributable to the extra-experimental sources of $R_{1}$, $R_{2}, R_{3}-n$, and extraneous (words not found in the Russell-Jenkins norm). The final column provides an account of the incidence of blanks. A total of 270 responses was used as the base for each group. Thus, for example, the value of .64 under correct responses in the 2-min group means that $64 \%$ of the 270 responses in this group were correct responses.

One of the major findings of the experiment is that, as predicted, the number of correct responses decreases significantly from $2 \mathrm{~min}$ to $48 \mathrm{~h}$, with the $48-\mathrm{h}$ group giving about one-half as many correct responses as the 2-min group. It was further predicted that as the probability of correct responses would decrease with time, the probability of primary responses would increase. This prediction was substantiated by data presented under $R_{1}$ in Table 2 . As the number of correct responses was halved $(64 \%$ to $31 \%)$, the number of $R_{1}$ words doubled ( $21 \%$ to $43 \%$ ). This latter difference, too, was found to be statistically significant. No significant difference was found between the groups in number of $R_{2}$ responses, of which relatively few were given, but a significantly greater number of $R_{3-n}$ responses was given in the 48-h group. The number of extraneous words and blanks was small in both groups and did not figure prominently in the results.

Discussion

The fact that the percentage of correct responses and the percentage of extra-experimental sources change over time in the direction of their free-association profile suggests that if the retention interval were long enough, the temporarily extinguished pre-experimental response associates would recover to full strength and eventually produce the .01 probability of a correct recall. However, such is not the case in a study recently reported by Bilodeau \& Blick (1965), who used similar training procedures and retention intervals up to 28 days. Thus, the findings of several studies using group training procedures indicate the strong effect of the training procedures, with a noticeable training residual even at the end of 28 days.

The present experiment substantiates the findings of Postman (1962) and Turnage (1963) that proacting influences from specific extra-experimental sources increase as the length of time between learning and recall increases, thus leading to an increase in verbal forgetting over time.

References

BILODEAU, E. A., \& BLICK, K. A. Courses of misrecall over long-term retention intervals as related to the strength of pre-experimental habits of word association. Percept. mot. Skills, 1965, 16, 1173-1192. (Monogr. Suppl, 6-V16)

BILODEAU, E. A., FOX, P. W., \& BLICK, K. A. Stimulated verbal recall and analysis of sources of recall. J. verbal Learn. verbal Behav., $1963,2,422-428$.

COLEMAN, E. B. The association hierarchy as an indicator of extraexperimental interference. J. verbal Leam. verbal Behav., 1963, 2, 427-421.

POSTMAN, L. The temporal course of proactive inhibition for serial lists. J. exp. Psychol, 1962, 63, 361-369.

RUSSELL, W. A., \& JENKINS, J. J. The complete Minnesota norms for responses to 100 words from the Kent-Rosanoff Word Association Test Tech. Rep. No. 11, 1954, Contract No. N80NR-66216, Office of Naval Research and University of Minnesota.

SPENCE, JANET T. Associative interference on paired-associate lists from extraexperimental learning. J. verbal Learn. verbal Behav., 1963, 2, 329-338.

TURNAGE, T. W. Pre-experimental associative probability as a determinant of retention. J. verbal Learn. verbal Behav., 1963, 2, 352-360.

UNDERWOOD, B. J., \& POSTMAN, L. Extraexperimental sources of interference in forgetting. Psychol. Rev., 1960, 67, 73-95.

Notes

1. Now at Purdue University.

2. Now at University of Richmond. 